\title{
PEMBERDAYAAN SANTRI MELALUI PELATIHAN BASIC LIFE SUPPORT
}

DOI: https://doi.org/10.33024/jkpm.v4i5.4211

\author{
Mukhammad Toha ${ }^{1 *}$, Ida Zuhroidah ${ }^{2}$, Mokh. Sujarwadi $^{3}$, Nurul Huda ${ }^{4}$ \\ Prodi D3 Keperawatan Fakultas Keperawatan \\ Universitas Jember Kampus Kota Pasuruan
}

Disubmit: 16 April 2021 Diterima: 04 Mei 2021 Diterbitkan: 01 Oktober 2021

Email: toha.akper@unej.ac.id

\begin{abstract}
ABSTRAK
Penyakit kardiovasuler merupakan penyakit yang menjadi ancaman dunia saat ini, di Indonesia menjadi penyakit ke-2 yang menyebabkan kematian. Di Dunia 17 juta lebih orang meninggal akibat penyakit jantung. Cardiac arrest merupakan kegawatdaruratan dari penyakit jantung yang akan menyebabkan kematian apabila pertolongan secara dini oleh orang awam tidak segera dilakukan. Tujuan dari resusitasi jantung paru yang dilakukan oleh orang awam adalah untuk mempertahankan fungsi vital. Apabila resusitasi jantung paru segera di lakukan, maka kelangsungan hidup mencapai $75 \%$. Tujuan pemberdayaan santri ini adalah agar santri menjadi garda terdepan dalam memberikan pertolongan pada orang yang berada disekitarnya ketika mengalami serangan jantung sehingga komplikasi dapat di minimalkan serta harapan hidup korban meningkat serta mampu melakukan tindakan resusitasi jantung paru secara tepat, cepat dan akurat. Metode yang digunakan pada pelatihan ini adalah ceramah dan diskusi serta praktik resusitasi jantung paru pada manekin yang dilakukan pada hari ke-2. Hasil dari pelatihan ini adalah sebagian besar (85\%) santri mengerti tentang konsep basic life support serta satu persatu santri mampu melakukan resusitasi jantung paru pada manekin.
\end{abstract}

Kata Kunci : pemberdayaan, santri, basic life support

\section{ABSTRACT}

Cardiovascular disease is a world threat today; in Indonesia, it is the second disease that causes death. In the world, more than 17 million people die from heart disease. Cardiac arrest is an emergency of heart disease that will cause death if ordinary people's early help is not immediately carried out. The goal of cardiac pulmonary resuscitation performed by the layman is to maintain vital functions. If cardiac pulmonary resuscitation is performed immediately, the survival rate is $75 \%$. The aim of empowering these students is to make the students at the forefront of providing help to those around them when they experience a heart attack so that complications can be minimized and the life expectancy of the victim increases and is able to perform cardiac pulmonary resuscitation actions appropriately, quickly and accurately. The methods used in this training were lectures and discussions as well as the practice of cardiopulmonary resuscitation on the mannequin which was conducted on the 
2nd day. The result of this training was that most of the students (85\%) understand the basic concept of life support and one by one one student able to perform cardiopulmonary resuscitation on the mannequins.

Keyword : empowerment, student, basic life support

\section{PENDAHULUAN}

Penyakit yang menjadi ancaman dunia (global threat) sampai saat ini adalah penyakit kardiovaskuler yang merupakan penyebab kematian nomor satu di Dunia (Firdaus, 2019). Menurut Word Health Organization (WHO) Tahun 2020, 17 juta lebih orang meninggal di dunia akibat penyakit jantung dan pembuluh darah dan penyakit TBC, malaria, HIV/AIDS secara keseluruhan menyebabkan kematian sekitar 3 juta populasi masyarakat di dunia. Data dari riset kesehatan desa (Riskesdas) Tahun 2018 menunjukkan bahwa terjadi peningkatan dari tahun ke tahun angka kejadian penyakit pembuluh darah dan jantung di mana 15 dari 1000 orang (4,2 juta) masyarakat di Indonesia mengalami penyakit jantung (Firdaus, 2019). Di Indonesia, penyakit jantung merupakan penyebab kematian terbanyak ke-2 (Kemenkes, 2019).

Jika pertolongan segera diberikan oleh orang sekitar, ketika pasien mengalami awal serangan, kemungkinan 31,7\% bertahan hidup. Komponen baik secara langsung maupun secara tidak langsung mempengaruhi keberhasilan resusitasi jantung paru meliputi mengidentifikasi serta pertolongan dini pada pasien, kualitas yang melakukan perolongan serta kualitas dari resusitasi yang diberikan. Ada hubungan yang signifikan antara pelatihan basic life support awam dengan pengetahuan, sikap serta ketrampilan peserta di Pondok Pesantren Gontor Kediri (Windy Ari Wijaya, 2017).

Kegawatdaruratan dari penyakit jantung adalah cardiac arrest, apabila tidak segera dilakukan pertolongan maka akan menyebabkan kematian. Rekomendasi dari AHA adalah segera dilakukan resusitasi jantung paru oleh orang awam untuk mempertahankan fungsi vital. Apabila resusitasi jantung paru segera di lakukan, maka kelangsungan hidup mencapai $75 \%$, apabila pertolongan dilakukan setelah lima menit dari cardiac arrest maka kelangsungan hidup mencapai 25\% (Kleinman et al., 2015). Menurut (Eko \& Setianingsih, 2020) menyatakan bahwa terdapat perbedaan pengetahuan sebelum dan sesudah dilakukan edukasi ( $\mathrm{p}$ value $=0,000$ ). Menurut (Al Fatih \& Rahmidar, 2021) metode low fidelity simulation merupakan metode pembelejaran yang efektif dalam meningkatkan pengetahuan dan ketrampilan mahasiswa ketrampilan dalam melakukan bantuan hidup dasar serta tidak ada pengaruh yang signifikan metode low fidelity simulation terhadap peningkatakan self-efficacy mahasiswa keperawatan tentang bantuan hidup dasar.

Pelatihan bantuan dasar sangat di butuhkan oleh masyarakat awam, termasuk santri yang tinggal di Pondok pesantren. Di Kota Pasuruan terdapat pondok pesantren modern dimana sistem pendidikan yang di gunakan adalah pendidikan formal (umum) serta pendidikan agama. Santri di pondok pesantren Bayt Al Hikmah dibekali berbagai ilmu baik pengetahuan umum maupun agama, akhalakhul karimah serta soft skill agar ketika keluar dari pondok bermanfaat di masyarakat. Sistem pendidikan di pondok pesantren Bayt Al Hikmah asrama, gedung sekolah, masjid dipisah antara santri laki-laki 
dengan santri perempuan. Pelatihan tentang kegawat daruratan penting dimiliki oleh santri, agar bisa di manfaatkan dalam pemberian pertolongan secara dini di lingkungan pondok maupun ketika berada di masyarakat umum (Zuhroidah et al., 2021). Menurut (Supriatna et al., 2020) ada pengaruh yang signifikan program poskestren pada perilaku hidup bersih dan sehat pada santri, sehingga perlu di buat perencanaan yang berkesinambungan serta terarah tentang program poskestren untuk mendapatkan hasil yang jauh lebih baik.

Tujuan dari kegiatan pemberdayaan santri ini adalah diharapkan santri menjadi garda terdepan dalam memberikan pertolongan pada orang yang berada disekitarnya ketika mengalami serangan jantung sehingga komplikasi dapat di minimalkan serta harapan hidup korban meningkat, serta santri mampu melakukan tindakan resusitasi jantung paru secara tepat, cepat dan akurat. Sesuai dengan latar belakang diatas, penulis tertarik melakukan pemberdayaan santri melalui pelatihan basic life support di Pondok Pesantren Bayt Al Hikmah Kota Pasuruan Jawa Timur.

\section{MASALAH}

Permasalahan yang ada di Pondok Pesantren Bayt Al Hikmah, adalah santri kurang memahami tentang pertolongan pertama jika terjadi serangan jantung atau tentang kegawatdaruratan. Pelayanan di Puskestren mulai jam 07.0020.00 WIB, sedangkan santri selama 24 jam di Asrama dengan jadwal yang padat sehingga kelelehan sering terjadi pada santri. Fasilitas kesehatan yang dekat dengan pondok pesantren, jarak tempuh adalah 10 menit.

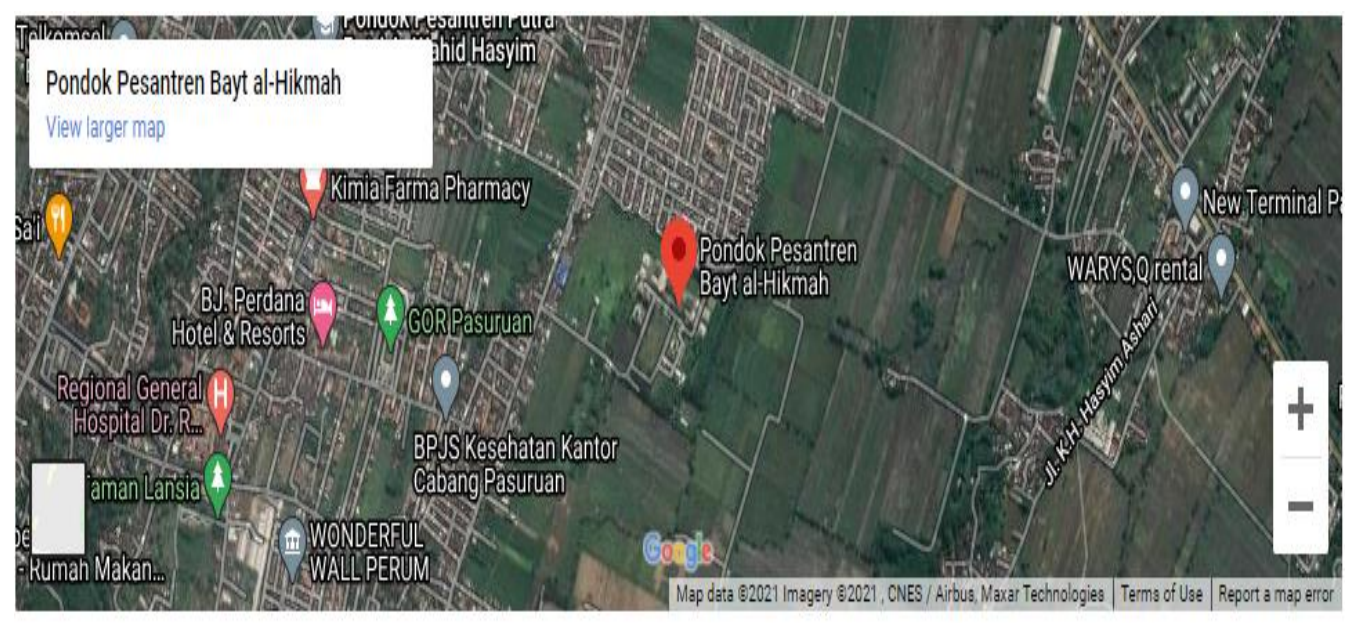

Gambar 2.1 Peta Lokasi Kegiatan

\section{METODE}

Metode yang digunakan pada kegiatan ini adalah metode pelatihan. Sebelum kegiatan pelatihan ini di mulai, maka kegiatan awal yang dilakukan adalah pembukaan pelatihan yang dilakukan oleh kepala pusat kesehatan pesantren (Puskestren). Kegiatan awal yang dilakukan pemateri adalah memperkenalkan diri serta menjelaskan tujuan dari pelatihan yang akan dilakukan selama dua hari. Kegiatan selanjutnya adalah menyampaikan materi serta pada hari kedua melakukan demonstrasi serta redemontrasi resusitasi jantung paru pada manekin. Media yang digunakan dalam pelatihan ini LCD serta manekin. 


\section{HASIL DAN PEMBAHASAN}

Kegiatan pelatihan basic life support ini dilaksanakan di gedung SMA Bayt Al Hikmah selama 2 hari, dan peserta pada kegiatan ini adalah 30 orang santri laki-laki pondok pesantren Bayt Al Hikmah. Kejadian henti jantung di luar Rumah Sakit, terjadi secara mendadak serta faktor penyebab sebagian besar karena penyakit jantung. Program pelatihan BLS lebih fokus pada out hospital cardiac arrest (OHCA) (Mancini et al., 2015). Peserta mengikuti pelatihan dengan baik serta berperan aktif dalam sesi diskusi, mengajukan pertanyaan tentang apa yang belum di pahami oleh santri. Kegiatan awal yang dilakukan oleh pemateri adalah menyampaikan tujuan dari kegiatan pelatihan ini, melakukan apersepsi santri tentang pertolongan pertama pada korban dengan serangan jantung. Pada kegiatan inti, pemateri menyampaikan tentang sistem sirkulasi, sistem pernafasan serta pertolongan pertama pada korban dengan serangan jantung. Pelatihan ini pada hari pertama pelaksanannya selama 5 jam dengan metode ceramah dan diskusi, hari kedua dilaksanakan praktek cara melakukan resusitasi jantung paru pada manekin dan semua santri mempunyai kesempatan yang sama untuk melakukan praktek resusitasi jantung paru pada manekin. Evaluasi yang dilakukan pada hari kedua, didapatkan hasil bahwa sebagian besar (85\%) santri mampu mempraktekkkan resusitasi jantung paru pada manekin dan mampu menjelaskan tentang sistem sirkulasi, pernafasan serta basic life support. Selama kegiatan, santri senang, hal ini terbukti dengan banyaknya santri yang mengajukan pertanyaan serta semua mau mencoba melakukan resusitasi jantung paru pada manekin dan berharap kegiatan ini bisa berlangsung secara kontinu. Untuk meningkatkan kepercayaan diri dalam melakukan tindakan resusitasi jantung paru, perlu dilakukan pelatihan secara kontinu dan dilaksanakan secara sistematis, mengingatkan pentingnya pelatihan BLS dalam menyelamatkan pasien ketika terjadi henti jantung (Abolfotouh et al., 2017). Kegaiatan ini terdokumentasikan dengan gambar sebagai berikut:

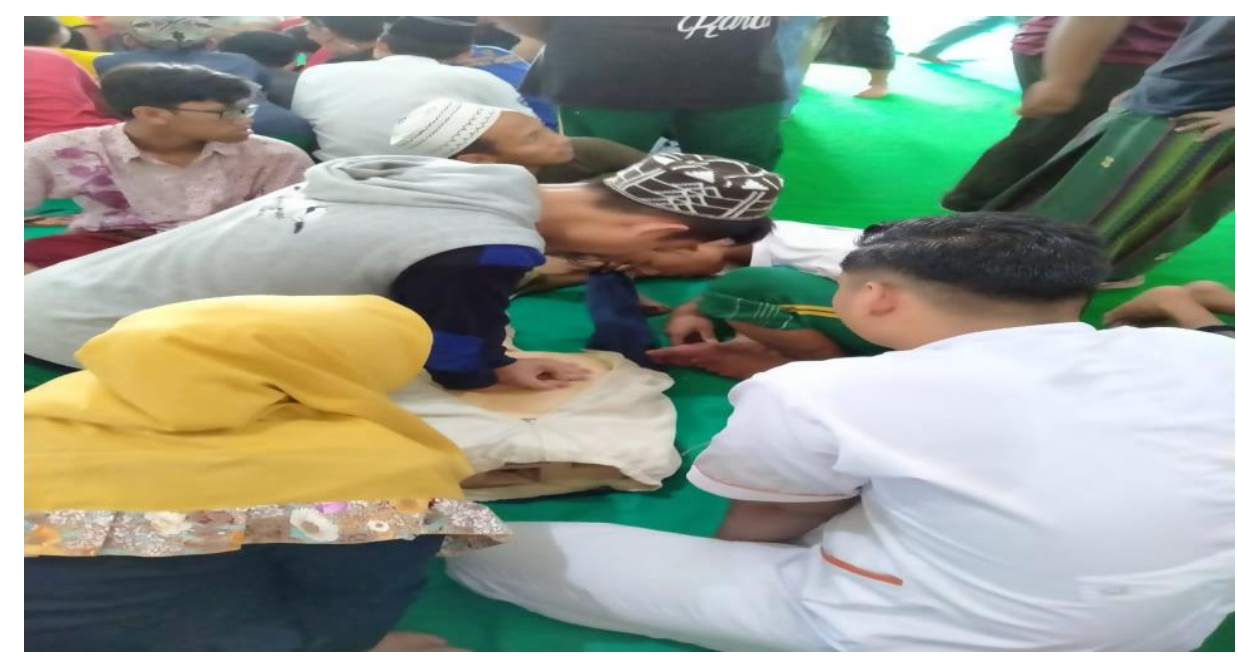

Gambar 4.1. Redemontrasi RJP 


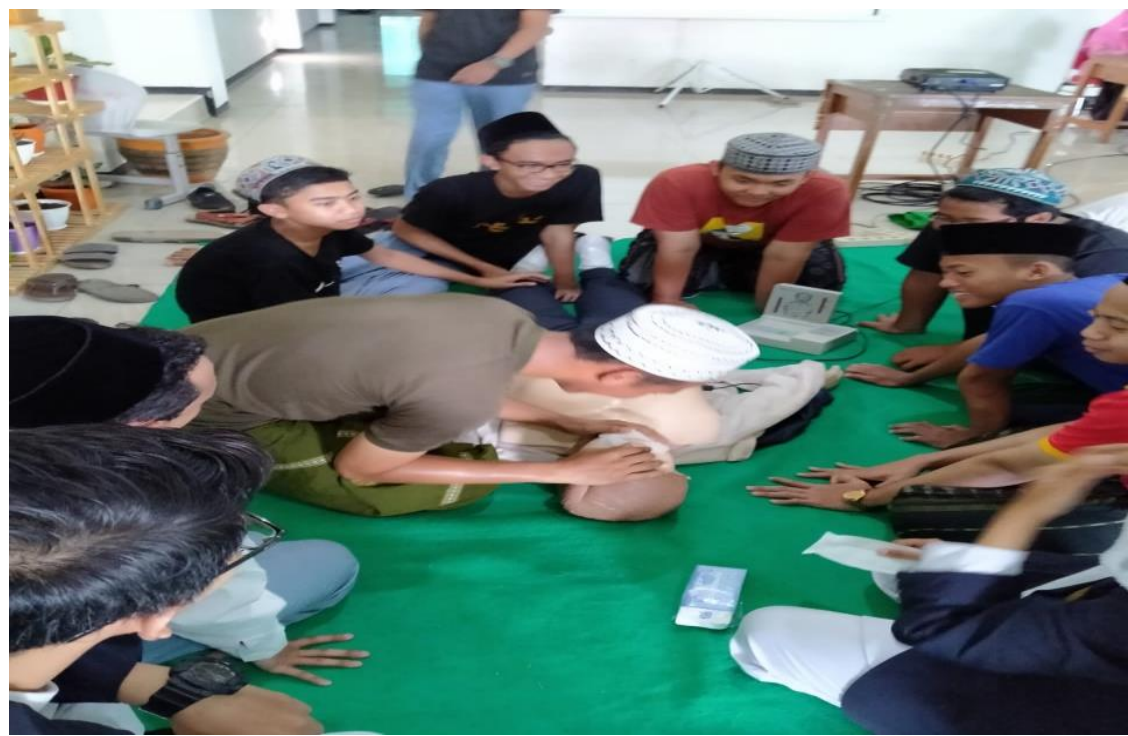

Gambar 4.2. Praktek RJP

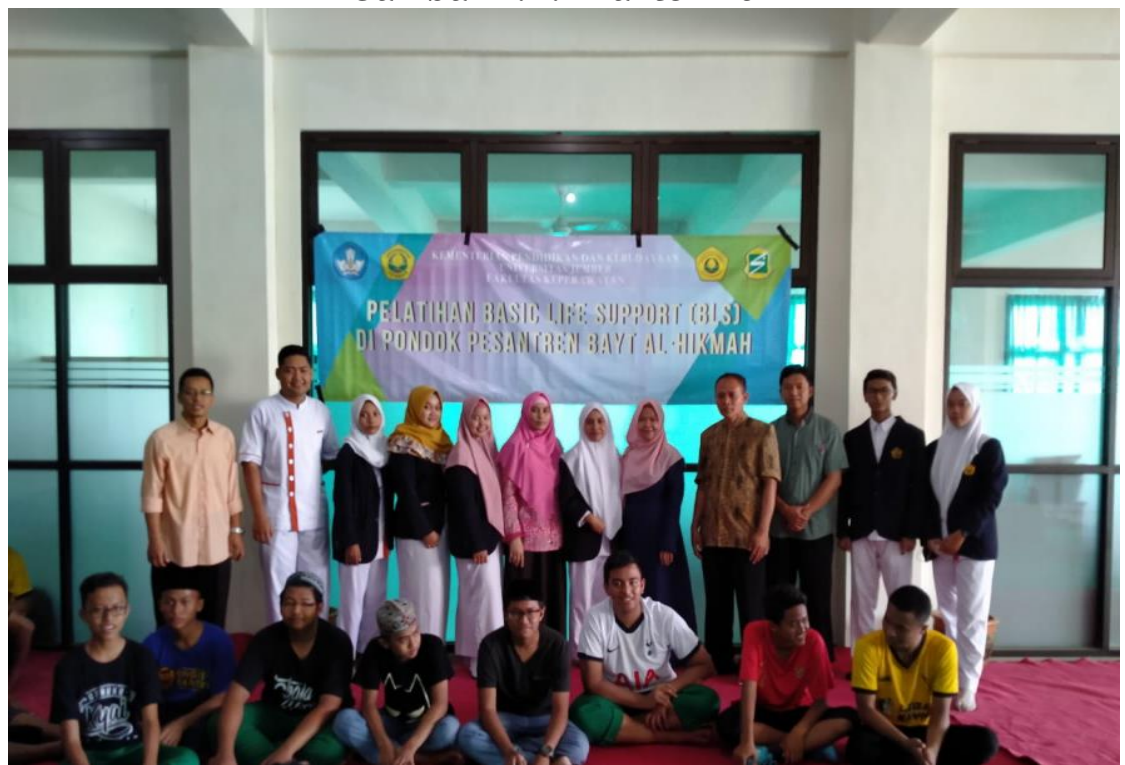

Gambar 4.3. Foto Bersama

\section{KESIMPULAN}

Setelah dilakukan kegiatan pengabdian, kesimpulan dari kegiatan ini adalah sebagian besar (85\%) santri mengerti tentang konsep basic life support serta melakukan pertolongan serangan jantung dengan resusitasi jantung paru pada manekin. Hasil evaluasi selama 2 hari didapatkan hasil bahwa 100\% santri terlihat aktif dalam mengikuti pelatihan, mengikuti pelatihan selama dua hari dan selama kegiatan pelatihan, tidak ada santri yang meninggalkan acara. Ketika sesi praktek RJP pada manekin, semua santri antusias mencoba praktikum. Untuk mengetahui peningkatan pengetahuan sebelum dan sesudah dilakukan pelatihan basic life support adalah dengan dilakukan evaluasi akhir serta menilai kemampuan peserta dalam melakukan pertolongan resusitasi jantung paru pada manekin. Ketika menemui orang di sekitarnya mengalami serangan jantung, santri akan melakukan pertolongan sesuai dengan teori yang di dapatkan selama 2 hari mengikuti pelatihan. 


\section{DAFTAR PUSTAKA}

Abolfotouh, M. A., Alnasser, M. A., Berhanu, A. N., Al-Turaif, D. A., \& Alfayez, A. I. (2017). Impact of basic life-support training on the attitudes of healthcare workers toward cardiopulmonary resuscitation and defibrillation. BMC Health Services Research, 17(1). https://doi.org/10.1186/s12913-017-26215

Al Fatih, H., \& Rahmidar, L. (2021). Efektivitas low fidelity simulation terhadap self-efficacy mahasiswa keperawatan dalam melakukan bantuan hidup dasar. Holistik Jurnal Kesehatan, 14(4), 590-595. https: / / doi.org/10.33024/hjk.v14i4.3159

Eko, L. D., \& Setianingsih. (2020). Peningkatan Pengetahuan Orang Awam Tentang Penanganan Out Of Hospital Cardiac Arrest Melalui Aplikasi Resusitasi Jantung Paru Pada Smartphone IMPROVEMENT OF KNOWLEDGE PEOPLE ABOUT HANDLING OUT OF HOSPITAL CARDIAC ARREST THROUGH THE APPLICATION OF LUNG HEA. Ilmiah STIKES Kendal, 10(1), 97-102.

Firdaus, I. (2019). Hari Jantung Sedunia (World Heart Day): Your Heart is Our Heart Too Perhimpunan Dokter Spesialis Kardiovaskular Indonesia ( P E R K I ). Press Release, 27 September 2019 - World Heart Day PERKI. http://www.inaheart.org/news_and_events/news/2019/9/26/press_relea se_world_heart_day_perki_2019

Kemenkes. (2019). Penyakit jantung penyebab kematian terbanyak ke-2 di indonesia. Kementrian Kesehatan Republik Indonesia. https://www.kemkes.go.id/article/view/19093000001/penyakit-jantungpenyebab-kematian-terbanyak-ke-2-di-indonesia.html

Kleinman, M. E., Brennan, E. E., Goldberger, Z. D., Swor, R. A., Terry, M., Bobrow, B. J., Gazmuri, R. J., Travers, A. H., \& Rea, T. (2015). Part 5: Adult Basic Life Support and Cardiopulmonary Resuscitation Quality. Circulation, 132(18 suppl 2), S414-S435. https://doi.org/10.1161/cir.0000000000000259

Mancini, M. E., Diekema, D. S., Hoadley, T. A., Kadlec, K. D., Leveille, M. H., McGowan, J. E., Munkwitz, M. M., Panchal, A. R., Sayre, M. R., \& Sinz, E. H. (2015). Part 3: Ethical issues: 2015 American Heart Association guidelines update for cardiopulmonary resuscitation and emergency cardiovascular care. Circulation, 132(18), S383-S396. https://doi.org/10.1161/CIR.0000000000000254

Supriatna, L. D., Indasah, I., \& Suhita, B. M. (2020). Program promotif poskestren terhadap PHBS santri di pondok pesantren. Holistik Jurnal Kesehatan, 14(3), 332-337. https: //doi.org/10.33024/hjk.v14i3.2741

Windy Ari Wijaya, -dr. (2017). Pengaruh Pelatihan Basic Life Support Awam TerhadapTingkat Pengetahuan, Keterampilan, SikapPada Pertolongan Hidup DasarDi Pondok Pesantren Gontor Kediri. http: //repository.unair.ac.id/64296/

Zuhroidah, I., Toha, M., Sujarwadi, M., \& Huda, N. (2021). Pengabdian Kepada Masyarakat Bantuan Hidup Dasar Pada Santri. Jurnal Kreativitas Pengabdian Kepada Masyarakat (Pkm), 4(2), 329-333. https://doi.org/10.33024/jkpm.v4i2.3733 